\title{
DESARROLLO DE LA CONCIENCIA FONÉMICA: EVALUACIÓN DE UN PROGRAMA DE INTERVENCIÓN
} DEVELOPMENT OF PHONEMIC AWARENESS:
ASSESSMENT OF AN INTERVENTION PROGRAM

\author{
Daniel Trías \\ Ariel Cuadro \\ Daniel Costa \\ Universidad Católica del Uruguay, Uruguay
}

\begin{abstract}
Resumen: En un estudio longitudinal se busca evaluar el impacto del entrenamiento en conciencia fonémica en la adquisición del lenguaje escrito. Participaron 51 niños de Educación Inicial. Se asignaron a tres condiciones experimentales: conciencia fonológica y grafemas, conciencia fonológica y grupo control. En distintos momentos de la escolaridad se evaluó: conciencia fonémica, reconocimiento de letras y de palabras y fluencia lectora. Iniciado Primer Año los participantes están ya familiarizados con el lenguaje escrito, alcanzan altos niveles de conciencia fonémica y reconocen palabras. Considerando la condición experimental, el grupo entrenado en conciencia fonológica y grafemas mantiene niveles más altos en segmentación y lectura de palabras, aunque la brecha no resulta estadísticamente significativa. Tampoco se observan diferencias al comparar la fluencia lectora en tercer año. Estos resultados deben interpretarse desde la relación causal bidireccional entre conciencia fonológica y lectura que acelera los procesos de desarrollo en una lengua transparente como el castellano.
\end{abstract}

Palabras clave: lectura, conciencia fonológica, habilidades metalingüisticas, conocimiento prelector.

\begin{abstract}
The present longitudinal study addresses the assessment of a training program on phonemic awareness in the acquisition of written language. Fifty-one preschool children participated in this research. The participants were assigned to three different experimental conditions: phonological awareness and graphemes, phonological awareness and control group. Throughout schooling, phonological awareness, letter and word recognition and reading fluency were assessed. Initiating the first year of primary school, the participants are already familiar with the written language, they reach higher levels of phonological awareness and word recognition. Regarding the experimental condition, the group trained in phonological awareness and graphemes sustains higher levels in segmentation and word reading, although the gap is not statistically significant. Additionally, differences are not observed when considering the reading fluency in third grade. These results shall be interpreted taking into consideration the bidirectional causal relationship between phonological awareness and reading, which accelerates the development process in a transparent language such as Spanish.
\end{abstract}

Keywords: reading, phonological awareness, meta-linguistic skills, preliterate knowledge.

\section{INTRODUCCIÓN}

Se presenta un estudio longitudinal cuyo objetivo es evaluar los efectos en el largo plazo de un programa de intervención para la estimulación de la conciencia fonémica a medida que los niños avanzan en su escolaridad y en la adquisición del lenguaje escrito. Se entrenó a un grupo de niños en tareas de conciencia fonémica mientras cursaban el último año de Educación Inicial. Se evaluó su reconocimiento de letras y conciencia fonológica en la fase previa y posterior a la intervención realizada en contexto de aula (Cuadro \& Trías, 2008). Pasado el tiempo, al comenzar primer año escolar se los volvió a evaluar en las mismas variables, a la vez se tomaron medidas de reconocimiento de palabras y de pseudopalabras. 
Por último, a los mismos sujetos se los evaluó en fluidez lectora mientras cursaban su tercer año escolar.

En Uruguay la adquisición de la lectura continúa siendo un problema para la práctica educativa, particularmente en poblaciones con alta vulnerabilidad social. En evaluaciones presentadas se observa que un $54,7 \%$ de los escolares en situación de riesgo social desconocen las letras o solo nombran algunas de ellas, sin llegar a reconocer palabras (ANEP, 2002). Por tanto, la posibilidad de evaluar los efectos de la intervención educativa en largo plazo tiene implicaciones prácticas en la búsqueda permanente de intervenciones educativas óptimas y oportunas para distintos contextos (Marchant, Lucchini \& Cuadrado, 2007). A su vez del estudio de intervención surgen consecuencias teóricas particularmente al analizar las relaciones entre conciencia fonológica y lectura en una lengua transparente como el castellano (Defior, 2008).

Especialmente en situaciones de mayor vulnerabilidad, el desconocimiento del principio alfabético es marcado. Esto se evidencia particularmente en sus bajos niveles de reconocimiento de letras y segmentación fonémica, redundando en sus magros resultados en lectura de palabras (Cuadro, Ilundain \& Puig, 2009; Nancollis, Lawrie, \& Dodd, 2005). Este descenso marcado impacta en otros procesos cognitivos, afectivos y sociales de suma relevancia ((Marchant, Lucchini \& Cuadrado, 2007).

Ya ha sido ampliamente analizado y constatado el papel que la conciencia fonológica tiene en la adquisición de la lectura en distintas lenguas y contextos culturales (Liberman \& cols., 1974; Morais, 1998). Sabido es que constituye una importante variable predictora antes de iniciar el aprendizaje lector propiamente dicho (Torgensen, Wagner \& Rashotte, 1994). A la vez, las dificultades específicas en la adquisición de la lectura se vinculan estrechamente a las dificultades en el desarrollo de la conciencia fonológica (Jiménez \& Ramírez, 2002; Serrano \& Defior, 2008).

En cuanto al desarrollo de la conciencia fonológica se postula que el mismo es consecuencia de las actividades de manipulación que los sujetos realizan sobre el lenguaje oral. El aprendizaje de la lectura exige ciertos niveles de desarrollo de la conciencia fonológica, y a la vez esta exposición al lenguaje escrito po- tencia niveles crecientes de la misma (Herrera \& Defior, 2005).

Se ha señalado que las características del lenguaje afectan el desarrollo de la conciencia fonológica (Defior, 2008; Goswami, 2002; Herrera \& Defior, 2005). En lenguas opacas como el inglés, el desarrollo de la conciencia fonológica se va dando progresivamente y mantiene un papel relevante durante los primeros años de escolaridad (Hatcher, Hulme \& Snowling, 2004; Serrano \& Defior, 2008). En cambio en lenguas trasparentes, se da un desarrollo temprano de la conciencia fonológica lo que facilita la adquisición de principio alfabético y consecuentemente acelera el desarrollo de la conciencia fonológica (Jiménez, Venegas \& García, 2007).

En cuanto a las formas de intervención en lengua castellana, se ha destacado que la conciencia fonológica es entrenable (BowyerCrane \& cols., 2008; González, 1996; Herrera, Defior \& Lorenzo, 2007). A la vez se requiere de enseñanza para el desarrollo de la misma. Las intervenciones más eficaces combinan actividades de manipulación de sonidos del lenguaje oral con la presentación explícita de los grafemas, pues contribuyen significativamente a la adquisición del principio alfabético (Defior, 2008; Herrera, Defior, \& Lorenzo, 2007). Esto se vuelve más significativo para los chicos que por variables constitucionales o culturales se encuentran en desventaja al iniciar el aprendizaje lector.

Existen menos estudios sobre los efectos de las intervenciones en el largo plazo, fundamentalmente analizando las consecuencias del entrenamiento en conciencia fonológica sobre las variables asociadas a la lectura (reconocimiento de palabras, fluidez lectora, etc.). Por ejemplo Herrera, Defior y Lorenzo (2007) informan que los efectos de un programa de intervención en conciencia fonológica son observados seis meses después de la intervención. En otro estudio Defior (2008), realizado con niños pre-lectores de habla castellana, se reportan efectos de un programa de entrenamiento en conciencia fonológica en medidas de lectura y de escritura al año de finalizada la intervención; aunque esos efectos no se mantienen al finalizar el segundo año.

Teniendo en cuenta la importancia de la intervención preventiva en el ámbito educativo se ha elaborado un programa de entrenamiento de la conciencia fonémica para niños en Educación Inicial, nivel 5 años (Cuadro, Trías, \& Castro, 2007). 
El mismo constituye una secuencia de actividades sobre los fonemas, que pueden ser realizadas en contexto de aula, con el objetivo de favorecer el desarrollo de niveles crecientes de conciencia fonémica y consecuentemente facilitar el aprendizaje lector.

Cuadro y Trías (2008), al evaluar la eficacia de dicho programa de intervención, aplicado en ocho semanas, encontraron efectos visibles en segmentación fonémica, cuando los niños aún cursaban el último año de la educación inicial. Conocer el impacto de esta intervención en el momento en que se produce la enseñanza explícita de la lectura y a medida que avanza su adquisición constituye una interrogante a despejar.

Resulta relevante conocer los impactos de dicho plan de intervención en el largo plazo, por tanto el objetivo principal de este trabajo es evaluar longitudinalmente los efectos de un programa de entrenamiento en conciencia fonémica en el primer y tercer año de la enseñanza primaria. Interesa particularmente conocer los efectos de la intervención en los sujetos que al inicio mostraban estar en una situación de mayor vulnerabilidad.

\section{MÉTODO}

\section{Participantes}

La muestra estuvo integrada por 51 niños que cursaban el último año de Educación Inicial (Nivel 5 años), en un colegio privado de nivel socioeconómico medio-alto de Montevideo. Se distribuían en $53 \%$ de sexo masculino y $47 \%$ de sexo femenino. La media de edad fue de 68 meses a la fecha de la evaluación inicial, oscilando entre 62 y 75 meses. En primer año fueron evaluados 49 sujetos y en tercero 46 , ya que abandonaron los sujetos que se retiraron del colegio.

\section{Instrumentos}

a) Programa de entrenamiento en Conciencia Fonémica (Cuadro, Trías \& Castro, 2007). En sus dos versiones propone el trabajo sobre las habilidades de manipulación de los fonemas. Está organizado 16 sesiones de media hora. Las distintas tareas, secuenciadas en orden de dificultad creciente, son: aislar, reconocer, segmentar, síntesis, adición, omisión y sustitución. En el programa combinado (PC) se presentaron explícitamente los grafemas. En el programa simple (PS) se trabajó solo a nivel fonémico (para una descripción más amplia puede consultarse Cuadro y Trías, 2008).

b) Prueba de Conciencia Fonémica (PCF, Jiménez \& Ortiz, 1998). Consta de cuatro tareas de análisis fonémico: i) síntesis de fonemas; ii) aislar el fonema inicial o final; iii) segmentación en fonemas; d) omisión del fonema inicial o final. Cada tarea incluye 15 palabras presentadas oralmente y en forma individual; su aplicación demanda entre 20 y 30 minutos.

C) Prueba de reconocimiento de letras (PROLEC; Cuetos, Rodríguez \& Ruano, 1998). Se presentaron a los niños 20 letras de goma, solicitando que digan su nombre o su sonido.

d) Prueba de lectura de Palabras y Pseudopalabras (PROLEC; Cuetos, Rodríguez \& Ruano, 1998). Se trata de una lista de 60 palabras que se solicita sea leídas en voz alta por cada sujeto poniendo en juego procesos de acceso y reconocimiento léxico. En dicha lista se alternan palabras frecuentes (PF), infrecuentes $(\mathrm{PI})$ y pseudopalabras (PS), a la vez que se discriminan en cortas o largas. Se considera la puntuación total de aciertos.

e) Test de Eficacia Lectora (TECLE; Cuadro, Costa, Trías \& Ponce, 2009). Consta de 64 ítems constituidos por frases incompletas, en los cuales el sujeto debe seleccionar la opción correcta entre cuatro posibles. Se dispone de cinco minutos para realizar la tarea y en su puntuación se consideran el número de aciertos en el tiempo dado, constituyendo una medida de fluencia lectora. Alcanzan en la prueba una mejor puntuación aquellos lectores que han automatizado en mayor medida los procesos de reconocimiento de palabras. Se trata de un test de velocidad, cuya fiabilidad utilizando un procedimiento de test-retest alcanza un valor de correlación de .88. En los estudios de validez criterial se obtiene un valor de .393 lo que evidencia una correlación significativa, positiva y moderada entre el juicio experto del maestro y el resultado de la prueba.

\section{Procedimiento}

En Nivel 5 de Educación Inicial, se realizó una evaluación pre y posttest administrando indivi- 
dualmente la PCF y la prueba de reconocimiento de letras. Ambas evaluaciones se realizaron en el colegio, habiendo solicitado las autorizaciones correspondientes. Se empleo un diseño de grupos aleatorios por bloques, de manera que los tres grupos experimentales resultaron equiparables, bloqueando la variable conciencia fonémica y verificando que no existían diferencias significativas entre los grupos al inicio (utilizando la prueba de Kruskal-Wallis). Cada grupo trabajo con una maestra y fue asignado a condiciones experimentales distintas: Programa combinado (PC); Programa simple (PS); Grupo Control (GC). Las sesiones de entrenamiento se desarrollaron en el ambiente de aula donde los niños se manejaban habitualmente, en una dinámica de taller que las maestras tenían prevista en su planificación (por más detalles puede consultarse en Cuadro \& Trías, 2008).

Al año siguiente y a dos semanas de iniciado primer año escolar se evaluó a todos los participantes que continuaban en el colegio utilizando las mismas pruebas anteriormente mencionadas y solicitándoles lectura en voz alta de la lista de palabras y pseudopalabras. Finalmente, en tercer año escolar se evaluó la fluidez lectora de los sujetos que permanecían en la institución.

\section{RESULTADOS}

Se ha utilizado el paquete estadístico SPSS 14.0 y en las distintas pruebas el nivel de confianza es mayor de $95 \%$. En relación al primer objetivo de evaluación en el largo plazo de los efectos del programa de intervención en conciencia fonémica, pueden observarse en la Tabla 1 las medias y desviaciones estándar de cada una de las principales variables evaluadas en Nivel 5 y en Primer año considerando la condición experimental.
Al comenzar primer año el reconocimiento de letras alcanza una media de 17,06 , correspondiendo a un $85 \%$ de aciertos en dicha prueba. $\mathrm{Al}$ analizar las diferencias entre las medias por condición experimental (ver Tabla 1), utilizando la prueba de Kruskal-Wallis, no se observan diferencias significativas. Tampoco resultan significativas las diferencias al comparar la evolución de los rendimientos en la evaluación inicial y en primer año, empleando la prueba de rangos de Wilcoxson. Es decir, el reconocimiento de letras no difiere entre las distintas condiciones experimentales al comenzar primer año.

Al considerar el desarrollo de la conciencia fonológica (ver Tabla 1), se observan rendimientos superiores en las tareas de conciencia fonémica en aquellos alumnos que han recibido el tratamiento combinado de conciencia fonológica y grafemas $(C F+G)$. Particularmente, este grupo alcanza los mejores resultados en la tarea de segmentación tal como al final de Nivel 5, logrando una media de 12,73 aciertos lo que constituye un $85 \%$ del total. Sin embargo, dichas diferencias con el resto de los grupos no resultan estadísticamente significativas, comparadas mediante la prueba $U$ de MannWhitney. Al iniciar primer año, las distintas condiciones experimentales no se diferencian significativamente en sus niveles de desarrollo de conciencia fonémica. Se ha reducido la brecha que mostraba el grupo entrenado en conciencia fonológica y grafemas, relacionada con una evolución sensible del resto de los sujetos (ver Figura 1).

Al analizar el acceso léxico mediante la lectura en voz alta de palabras y pseudopalabras al iniciar primer año (ver Tabla 1), se observa que las medias más altas considerando globalmente la lista las obtiene el grupo que en Nivel 5 recibió entrenamiento explícito en conciencia fonológica y grafemas, a la vez el rendimiento es más homogéneo.

Tabla 1. Medias y desviaciones estándar de las distintas variables por curso escolar y condición experimental

\begin{tabular}{|l|ccc|ccc|}
\cline { 2 - 8 } \multicolumn{1}{c|}{} & \multicolumn{3}{c|}{ Nivel 5 } & \multicolumn{3}{c|}{ Primer año } \\
\cline { 2 - 8 } & CF+G & CF & C & CF+G & CF & C \\
& $\mathrm{N}=17$ & $\mathrm{~N}=17$ & $\mathrm{~N}=17$ & $\mathrm{~N}=15$ & $\mathrm{~N}=17$ & $\mathrm{~N}=17$ \\
\hline Reconocimiento & 16,88 & 13,71 & 15,88 & 17,73 & 16,29 & 17,23 \\
de Letras & $(1,22)$ & $(5,65)$ & $(2,55)$ & $(1,33)$ & $(4,31)$ & $(2,39)$ \\
\hline Segmentación & 12,41 & 10,65 & 7,00 & 12,73 & 11,53 & 10,12 \\
fonémica* & $(2,85)$ & $(4,17)$ & $(5,00)$ & $(2,96)$ & $(4,39)$ & $(4,57)$ \\
\hline Lectura de palabras & - & - & - & 46,27 & 37,41 & 36,94 \\
y pseudopalabras & - & - & - & $(12,74)$ & $(18,94)$ & $(22,35)$ \\
\hline
\end{tabular}

*las diferencias entre las medias en N5 resultan estadísticamente significativas 


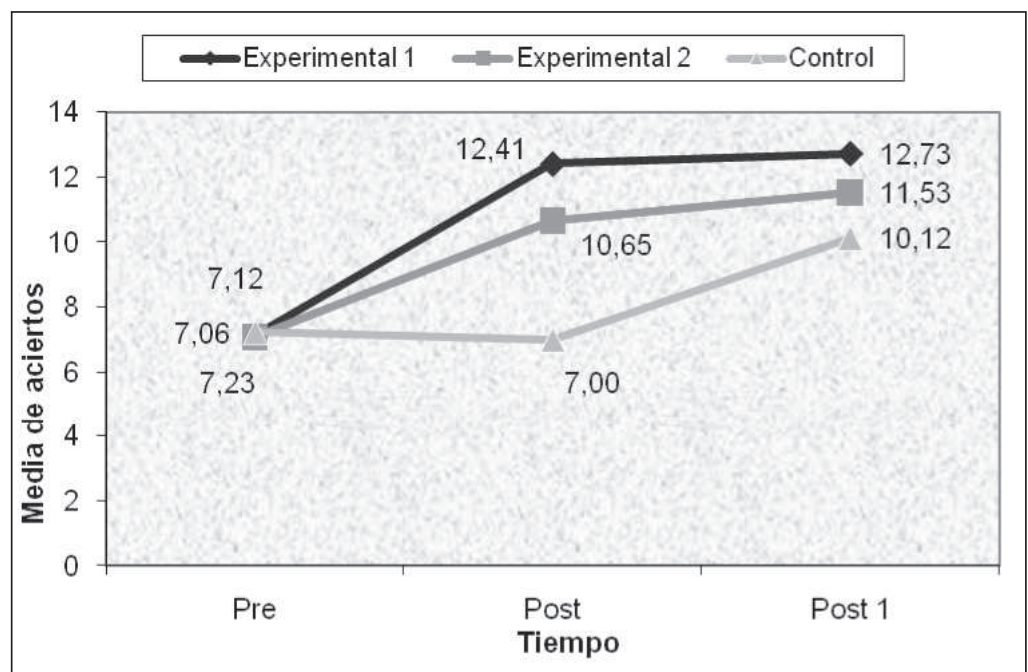

Figura 1. Evolución de las medias de segmentación por condición experimental

Por el contrario el grupo control muestra los desempeños más descendidos en lectura de palabras y pseudoplabras y la dispersión es mayor (ver Figura 2). Al valorar estas diferencias usando la prueba de Kruskal-Wallis no se aprecian diferencias significativas entre las distintas condiciones experimentales.

De la evaluación realizada en Primer Año escolar resulta que los alumnos que participaron del grupo experimental entrenado en CF y grafemas obtiene niveles de rendimiento mayor en reconocimiento de letras, segmentación de fonemas y lectura de palabras y pseudopalabras.
Sin embargo estas diferencias no resultan estadísticamente significativas. Al promediar el Tercer Año escolar se realizó la evaluación de la variable fluencia lectora (ver Tabla 2; p. 182). Al comparar las medias de las distintas condiciones experimentales, empleando la prueba KruskalWallis no se observan diferencias estadísticamente significativas. Curiosamente quienes alcanzan una media mayor en esta instancia de evaluación son los alumnos del grupo control. A medida que avanza el tiempo y los cursos escolares el efecto del programa de intervención en conciencia fonémica tiende a diluirse.

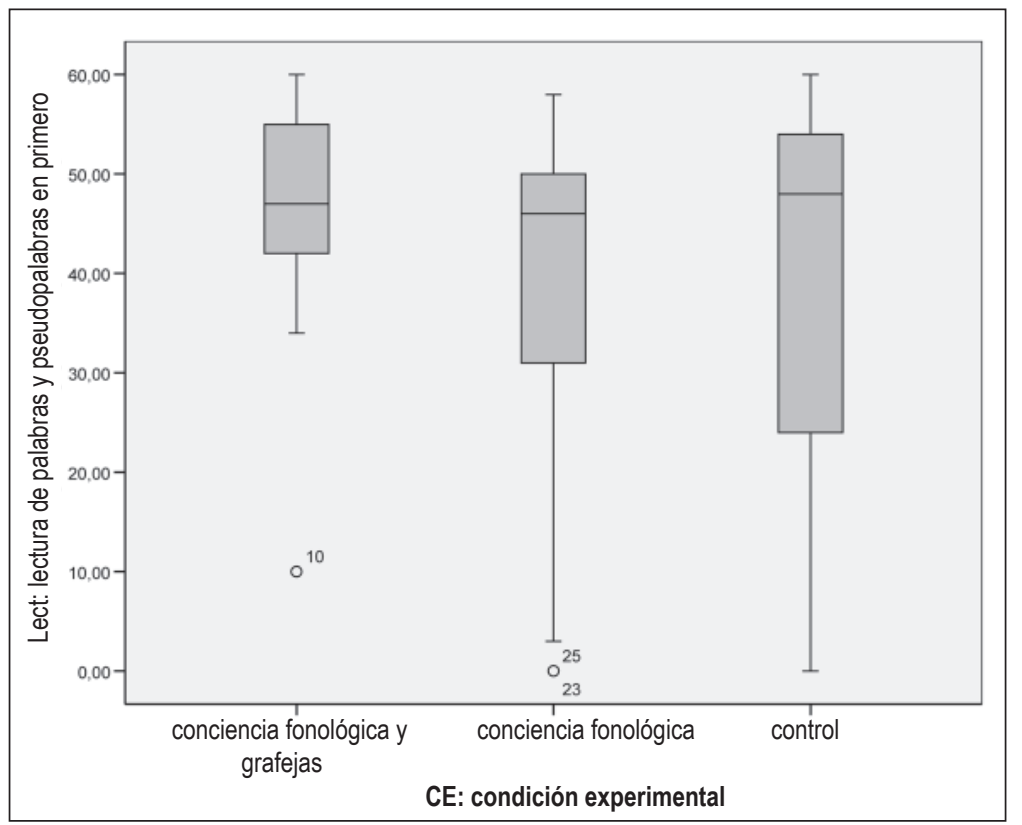

Figura 2. Distribución de puntuaciones en la lectura de palabras y pseudopalabras según condición experimental 
Tabla 2. Medias y desviaciones estándar de la fluencia lectora evaluada en Tercer Año

\begin{tabular}{|l|lcc|}
\cline { 2 - 4 } \multicolumn{1}{c|}{} & \multicolumn{3}{c|}{ Tercer año } \\
\cline { 2 - 4 } \multicolumn{1}{c|}{} & CF+G & CF & C \\
& $\mathrm{N}=15$ & $\mathrm{~N}=15$ & $\mathrm{~N}=16$ \\
\hline Fluencia & 24,87 & 21,87 & 28,37 \\
lectora (TECLE) & $(8,10)$ & $(5,23)$ & $(9,91)$ \\
\hline
\end{tabular}

En relación al segundo objetivo que procura evaluar el impacto del programa de intervenciones en aquellos sujetos que partieron de mayor vulnerabilidad, se considero a aquellos sujetos que conformaban el cuartel inferior en la prueba de segmentación.

En la Tabla 3 puede observarse cómo se distribuían estos participantes previamente a la intervención y luego de la misma. Inmediatamente finalizada la intervención, utilizando el mismo criterio, la distribución es diferente. La cantidad de sujetos en el cuartil inferior del grupo experimental $(C F+G)$ se reduce notoriamente, también se reduce en el grupo experimental (CF). En tanto, en el grupo control hay mayor proporción de sujetos en el cuartil inferior considerando la segmentación fonémica. El entrenamiento en conciencia fonémica ha beneficiado particularmente a aquellos que partían de una situación desventajosa. A partir de la intervención una proporción menor de sujetos del grupo experimental $(C F+G)$ se encuentra en niveles de riesgo.

Tabla 3. Cantidad y porcentaje de participantes en el cuartel inferior de segmentación por condición experimental

\begin{tabular}{|l|c|c|c|}
\cline { 2 - 4 } \multicolumn{1}{c|}{} & $\begin{array}{c}\text { Experimental } \\
(\mathbf{C F}+\mathbf{G}) \\
(\mathrm{n}=17)\end{array}$ & $\begin{array}{c}\text { Experimental } \\
(\mathrm{CF}) \\
(\mathrm{n}=17)\end{array}$ & Control \\
\hline Evaluación Inicial & 5 & 5 & 3 \\
& $29,4 \%$ & $29,4 \%$ & $17,6 \%$ \\
\hline $\begin{array}{l}\text { Evaluación Final } \\
\text { (Nivel 5) }\end{array}$ & 1 & 3 & 10 \\
\hline
\end{tabular}

\section{DISCUSIÓN Y CONCLUSIONES}

Un objetivo principal del trabajo presentado fue evaluar en el largo plazo los efectos del plan de intervención para el desarrollo de la conciencia fonémica realizado en el Nivel 5 de Educación Inicial. Con tal propósito se han analizado distintas variables relacionadas a la adquisición de la lectura (reconocimiento de letras, conciencia fonémica, acceso léxico y fluidez lectora) en distintos momentos de la escolaridad.

En primer término, al considerar el reconocimiento de letras en Primer Año se ha observado un alto porcentaje de aciertos en el promedio de los participantes, independientemente de la condición experimental en la que hubieran participado previamente. Ha sido señalado que a medida que progresa el conocimiento lector, aumenta el dominio de las habilidades metafonológicas, avalando la hipótesis de la interacción recíproca entre conciencia fonológica y lectura (Herrera \& Defior, 2005; Jiménez, Venegas \& García, 2007). Por ejemplo, se ha señalado la relación que el conocimiento de las letras tiene en niños prelectores con las segmentación fonémica (Carroll, 2004). De este modo deberá considerarse el alto nivel de reconocimiento de letras al analizar la evolución del resto de las variables implicadas.

Así mismo esto datos evidencian la familiaridad con el código escrito que tienen los participantes del estudio ya desde la evaluación inicial, probablemente atribuible al contexto socioeconómico del que provienen. Estos niveles marcan claras brechas con lo ocurre en otros contextos. Los niños de contextos socioeconómicos desfavorecidos que inician primer año se encuentran en clara desventaja (Cuadro, Ilundain \& Puig, 2009; Nancollis, Lawrie, \& Dodd, 2005), y probablemente serían los que más se beneficiarían con intervenciones que contribuyan a su desarrollo metafonológico.

En segundo lugar, analizado el rendimiento en pruebas de conciencia fonémica en Primer Año se observan medias altas. Estos resultados se vinculan con aquellos estudios que muestra el desarrollo temprano y acelerado de la conciencia fonológica en castellano (Herrera, \& Defior, 2005; Jiménez, Venegas, \& García, 2007). Al comparar los rendimientos en segmentación fonémica según condición experimental, se observa un mejor desempeño del grupo $\mathrm{CF}+\mathrm{G}$. Intervención mediante, este grupo ya en el Nivel 5 de Educación Inicial había alcanzado altos niveles de desempeño en las tareas propuestas (Cuadro \& Trías, 2008) y superiores al resto de las condiciones experimentales. Su desempeño ya no podría mejorar demasiado. En Primer Año, la brecha en segmentación entre las condiciones experimentales se reduce y ya no resulta significativa. 
En este período se observan mejoras en el desempeño del grupo control, probablemente atribuible a la enseñanza en un contexto rico en estimulación. Una vez más debe recordarse la interacción entre el conocimiento de letras y las habilidades de segmentación fenémica (Carroll, 2004).

Los porcentajes de acierto en tareas de segmentación de los participantes del estudio atribuibles a sus niveles de desarrollo en conciencia fonémica, contrastan con el $11 \%$ de aciertos que logran chicos en situación de pobreza evaluados en tareas similares mientras cursan primer año (Cuadro, Ilundain \& Puig, 2009). Este contraste de resultados subraya la relevancia de intervenciones preventivas en contextos socioeconómicos desfavorecidos para facilitar el aprendizaje lector.

En tercer lugar, evaluado el acceso léxico a través de la lectura en voz alta de lista de palabras y pseudopalabras, son los alumnos que participaron de la intervención combinada $C F+G$, los que alcanzan los mejores desempeños. A la vez conforman un grupo más homogéneo, con menor dispersión de sus desempeños. De todos modos este mejor desempeño no resulta estadísticamente significativo. Los efectos que se observaban en segmentación fonémica inmediatamente finalizada la intervención, no se trasladan de forma evidente al reconocimiento de palabras unos meses después. Debe recordarse que se están comparando niños sin dificultades manifiestas, con familiaridad con el lenguaje escrito y en un contexto rico en estimulación.

Los altos niveles de desarrollo de conciencia fonológica, así como la ausencia de diferencias significativas entre los grupos deben ser interpretados desde la interacción recíproca entre lectura y conciencia fonológica. Alcanzados ciertos umbrales en el desarrollo de la conciencia fonológica, se acelera el proceso lector, que a su vez redunda en el desarrollo de la misma (Defior, 2008). Este proceso se da rápidamente en lenguas trasparentes, consistentes ortográficamente como el castellano (Goswami, 2002).

Hasta aquí se ha señalado que los efectos observados en segmentación fonémica inmediatamente finalizada la intervención, no se sostienen al comenzar Primer Año, ni se trasladan sensiblemente al reconocimiento de palabras. El contacto con el principio alfabético en lenguas transparentes es la clave. Que se diluyan los efectos obliga a pensar el valor y el momento de la intervención, sobretodo para quienes encuentran dificultades en el aprendizaje de la lectura (Defior, 2008). Parafraseando a Defior (2008) la conciencia fonológica operaría como catalizador contribuyendo a generar un contexto más amigable para el aprendizaje del lenguaje escrito.

Por último, ya en tercer año no se deberían encontrar diferencias entre las condiciones experimentales evaluada la fluidez lectora. De hecho no se observan diferencias significativas entre los grupos. Es razonable pensar que la intervención educativa de los primeros años de la escolaridad, resulta más poderosa que una intervención de tan solo 16 horas de clase realizada en forma complementaria. Raro sería que esa intervención determinara absolutamente el destino del aprendizaje lector.

En relación al segundo objetivo, debe recordarse que la estimulación en conciencia fonológica ha beneficiado en primera instancia a aquellos que partieron de una condición de mayor vulnerabilidad. Esto ha sido visible en el desempeño en segmentación fonémica que alcanzan los participantes del grupo experimental entrenado en conciencia fonológica y grafemas. Dichos logros colocan en mejores condiciones de iniciar el aprendizaje de la lectura a aquellos sujetos que estaban en desventaja.

En cuanto a los principales límites del presente estudio debe señalarse que se trata de una intervención educativa realizada en un contexto estimulante, lo cual dificulta el máximo control de variables. Los niños en su mayoría venían trabajando y lo siguieron haciendo con sus maestras de acuerdo al programa que en el colegio está pautado incluyendo actividades de conciencia fonológica. Ya se ha señalado la familiaridad con el código escrito que evidenciaron los participantes desde el inicio del estudio, esto ha dificultado la posibilidad de aislar más claramente la conciencia fonológica y la lectura.

Otro de los límites observados es que la medida de lectura utilizada es solamente de precisión de las palabras. Probablemente sería bueno contar con el dato del tiempo, pues quizá contribuiría a diferenciar mejor los desempeños en esta etapa de acceso léxico. Tampoco se ha indagado en el papel de otras variables como velocidad de procesamiento, velocidad de nominación, memoria verbal que se han mostrado como variables asociadas a la adquisición de la lectura. 
A futuro se considera relevante por razones prácticas y teóricas, el poder implementar y evaluar formas de intervención para el desarrollo de la conciencia fonológica en contextos desfavorecidos dada la magnitud de la brecha en las variables relacionadas con el aprendizaje lector. Así mismo se entiende necesario seguir buscando formas más ajustadas de intervención a los contextos de mayor vulnerabilidad.

En resumen, se ha procurado evaluar un programa de entrenamiento en conciencia fonémica a lo largo del tiempo, fundamentalmente analizando sus consecuencias sobre el aprendizaje lector. Finalizada la intervención, los efectos de la misma se evidencian en las habilidades para segmentar las palabras; lo cual facilitaría el aprendizaje lector de los sujetos más vulnerables. En primer año, se diluyen los efectos en las habilidades de conciencia fonémica y tampoco se diferencian significativamente los desempeños en reconocimiento de palabras. Dichos resultados se interpretan a la luz del rápido desarrollo de la conciencia fonológica en castellano, la interacción recíproca que existe entre conciencia fonológica y lectura, y la rica estimulación que ofrece el entorno.

\section{REFERENCIAS}

ANEP, Administración Nacional de Educación Pública. (2002). Los niveles de desempeño al iniciar la educación primaria. Estudio de las competencias lingüísticas y matemáticas. Evaluación Nacional en el Primer Nivel de la Escolaridad. Primer Informe.

Bowyer-Crane, C., Snowling, M. J., Duff, F. J., Fieldsend, E., Carroll, J. M., Miles, J., et al. (2008). Improving early language and literacy skills: differential effects of an oral language versus a phonology with reading intervention. Journal Of Child Psychology And Psychiatry, And Allied Disciplines, 49 (4), 422-432.

Carroll, J. M. (2004). Letter knowledge precipitates phoneme segmentation, but not phoneme invariance. Journal of Research in Reading, 27 (3), 212-225.

Cuadro, A., Costa, D., Trías, D., y Ponce de León, P. (2009). Manual Técnico del Test de Eficacia Lectora (TECLE). Montevideo: Prensa Médica.

Cuadro, A., Ilundain, A., y Puig, A. (2009).Habilidades prelectoras de niños en situación de pobreza.

Cuadro, A., y Trías, D. (2008). Desarrollo de la conciencia fonémica: evaluación de un programa de intervención. RevistaArgentina de Neuropsicología, 11, 1-8.

Cuadro, A., Trías, D., y Castro, C. (2007). Ayudando a futuros lectores. Montevideo: Prensa Médica Latinoamericana.
Cuetos, F., Rodríguez, B., y Ruano E. (1998). PROLEC. Evaluación de los procesos lectores. Madrid: TEA.

Defior, S. (2008) ¿Cómo facilitar el aprendizaje inicial de la lectoescritura? Papel de las habilidades fonológicas. Infancia y Aprendizaje, 31 (3), 333-345.

González, M. (1996). Aprendizaje de la lectura y conocimiento fonológico: análisis evolutivo e implicaciones educativas. Infancia y aprendizaje, 76, 97-107.

Goswami, U. (2002). Phonology, Reading Development, and Dyslexia: A Cross-Linguistic Perspective. Annals of Dyslexia, 52, 141.

Hatcher, P., Hulme, CH., y Snowling, M. (2004). Explicit phoneme training combined with phonic reading instruction helps young children at risk of reading failure. Journal of Child Psychology and Psychiatry, 45, 2, 338-358.

Herrera, L., y Defior, S. (2005). Una aproximación al procesamiento fonológico de los niños prelectores: conciencia fonológica, memoria verbal a corto plazo y denominación. Psykhe, 14, 2, 81-95.

Herrera, L., Defior, S., y Lorenzo, O. (2007). Intervención educativa en conciencia fonológica en niños prelectores de lengua materna española y tamazight. Comparación de dos programas de entrenamiento. Infancia y Apendizaje, 30 (1), 39-54.

Jiménez, J. E., Venegas, E., y García, E. (2007). Evaluación de la conciencia fonológica en niños y adultos iletrados: ¿es más relevante la tarea o la estructura silábica? Infancia y Aprendizaje, 30 (1), 73-86.

Jiménez, J. E., y Ortiz, M. (1998). Conciencia fonológica y aprendizaje de la lectura: Teoría, evaluación e intervención. Madrid: Síntesis.

Jiménez, J. E., y Ramírez, G. (2002). Identifying subtypes of reading disability in the spanish language. The Spanish Journal of Psychology, 5, 1, 3-19.

Liberman, I. Y., Shankweiler, D., Fischer, F. W., y Carter, B. (1974). Explicit syllable and phoneme segmentation in the young child. Journal of Experimental Child Psychology, 18 (2), 201-212.

Marchant, T., Lucchini, G., y Cuadrado, B. (2007). ¿Por qué Leer Bien es Importante?: Asociación del Dominio Lectorcon OtrosAprendizajes. Psykhe, 16(2), 3-16.

Morais, J. (1998). El arte de leer. Madrid: Visor.

Nancollis, A., Lawrie, B.-A., y Dodd, B. (2005). Phonological Awareness Intervention and the Acquisition of Literacy Skills in Children from Deprived Social Backgrounds. Language, Speech, \& Hearing Services in Schools, 36 (4), 325-335.

Serrano, F., y Defior, S. (2008). Dyslexia speed problems in a transparent orthography. Annals of Dyslexia, 58 (1), 81-95.

Torgensen, J., Wagner, R., \& Rashotte, C. (1994). Longitudinal Studies of phonological proccesing and reading. Journaloflearning disabilities, 27,5,276-286. 